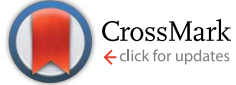

Cite this: J. Mater. Chem. A, 2015, 3, 22656

Received 15th August 2015

Accepted 29th September 2015

DOI: $10.1039 / \mathrm{c} 5 \mathrm{ta0} 6414 \mathrm{~g}$

www.rsc.org/MaterialsA

\section{Use of a protic salt for the formation of liquid- crystalline proton-conductive complexes with mesomorphic diols $\uparrow$}

\author{
Akihiro Yamashita, ${ }^{a}$ Masafumi Yoshio, ${ }^{\text {a }}$ Bartolome Soberats, ${ }^{\text {ab }}$ Hiroyuki Ohno ${ }^{c}$ \\ and Takashi Kato*ab
}

\begin{abstract}
We herein report that molecular assembly of wedge-shaped mesomorphic diols and a protic salt results in the formation of anhydrous one-dimensional (1D) and 2D proton-conductive materials. The protic salt has been obtained by stoichiometric neutralization of imidazole with benzenesulfonic acid. The protic salt is incorporated into the hydrogen-bonded networks of the hydroxyl groups of the mesomorphic diols. This confined protic salt in the nanochannels exhibits enhanced ionic conductivities by three-orders of magnitude compared with those of the pure protic salt in the solid state, indicating that the imidazolium salt forms a mobile state in the liquid-crystalline nanostructures. These self-assembled and ordered materials based on protic salts may be promising candidates for the application as anhydrous protonconducting electrolytes in fuel cells.
\end{abstract}

\section{Introduction}

Proton $^{-1-4}$ and anion ${ }^{5}$-conductive organic materials have attracted much attention for application as electrolytes in fuel cells. A representative example of proton-conductive polymers is sulfonic acid-functionalized polymers such as Nafion. ${ }^{6}$ They exhibit high proton conductivity in the presence of mobile water molecules. However, the conductivity gradually decreases due to the loss of water. Hence, it is crucial to design anhydrous electrolytes forming continuous pathways for ions. ${ }^{7-29}$ An attractive approach is the use of amphoteric nitrogen-containing heterocycles such as imidazoles and triazoles. ${ }^{13-15}$ Protic ionic liquids and protic salts obtained from the stoichiometric neutralization of Brønsted bases with acids have also received significant interest as alternative anhydrous electrolytes because of their non-volatility and thermal stability. ${ }^{\mathbf{1 6 - 2 2}}$ The design of network structures involving protons is essential to permit efficient proton conduction in these protic materials.

A promising approach to the construction of ion-conductive pathways is to make use of the self-assembly of liquid crystals owing to the spontaneous formation of ordered nanostructures and the alignability by external stimuli. ${ }^{7-10}$ A variety of proton-

${ }^{a}$ Department of Chemistry and Biotechnology, School of Engineering, The University of Tokyo, Hongo, Bunkyo-ku, Tokyo 113-8656, Japan. E-mail: yoshio@chembio.t.u-tokyo. ac.jp; kato@chiral.t.u-tokyo.ac.jp

${ }^{b}$ CREST, JST, 4-1-8, Honcho, Kawaguchi, Saitama 332-0012, Japan

${ }^{\circ}$ Department of Biotechnology, Tokyo University of Agriculture and Technology, Nakacho, Koganei, Tokyo 184-8588, Japan

$\dagger$ Electronic supplementary information (ESI) available: XRD, ${ }^{13} \mathrm{C}$ NMR, and IR spectra of the mixtures; analysis of self-assembled columnar structures. See DOI: $10.1039 / \mathrm{c} 5$ ta06414g conductive liquid crystals have been developed. ${ }^{23-30}$ For example, octadecylphenylsulfonic acid ${ }^{23}$ and biphenyl-based sulfonic acids ${ }^{\mathbf{2 4 , 2 5}}$ in the smectic A phases were reported to show enhanced anhydrous proton conductivities on the order of $10^{-3}-10^{-2} \mathrm{~S} \mathrm{~cm}^{-1}$. The proton conductivity of discotic mesogens bearing triazole moieties at their termini was examined and the conductivities ranged from $10^{-7}$ to $10^{-5} \mathrm{~S} \mathrm{~cm}^{-1} \cdot{ }^{26} \mathrm{We}$ also recently developed a new type of anhydrous protonconductive bicontinuous cubic liquid-crystalline material composed of a zwitterionic liquid crystal containing an ammonium sulfobetaine moiety and benzenesulfonic acid. ${ }^{30}$ Due to the formation of an ionic complex between the ammonium cation and the benzenesulfonate anion while the proton

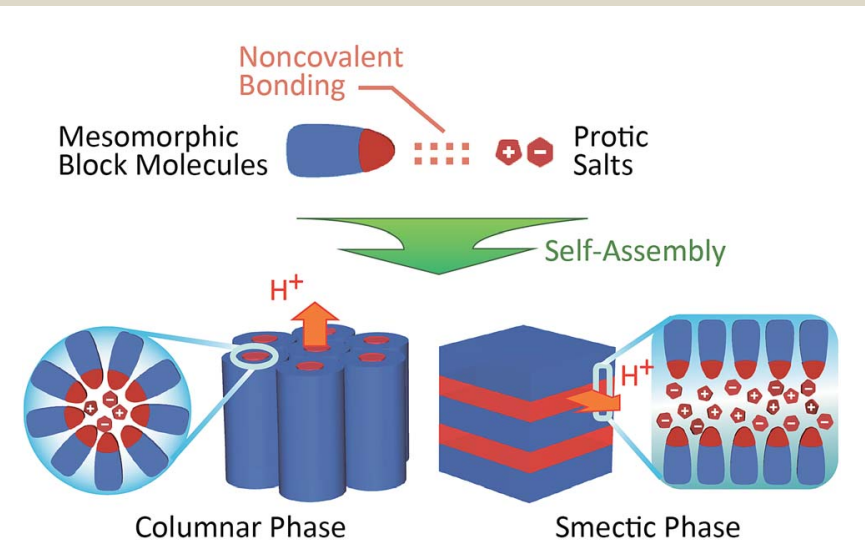

Fig. 1 Schematic illustration of the design of nanostructured anisotropic electrolytes by self-assembly of mesomorphic block molecules and protic salts. 
interacts with the sulfonate anion of the betaine moiety, a significant increase of proton conductivity was achieved for the complexes, although the zwitterionic liquid crystal alone has no transportable ions. Our intention in the present study is to develop nanostructured anisotropic electrolytes by noncovalent self-assembly of protic salts and mesomorphic block molecules into columnar and smectic phases and to achieve enhanced proton conductivity (Fig. 1).

Previously we developed nanostructured two-component ion-conductive liquid crystals consisting of ionic liquids and mesogenic compounds with either hydroxyl, ${ }^{31-36}$ imidazolium, ${ }^{37-39}$ or cyclic carbonate ${ }^{40}$ moieties. Only a few ionic liquids containing relatively hydrophilic anions such as bromide, iodide, and tetrafluoroborate anions showed miscibility with these functionalized mesogenic compounds. Depending on the molecular structures and mixing ratios, these binary mixtures formed columnar, layered, and bicontinuous cubic liquid-crystalline structures with one-dimensional (1D), 2D, and 3D ionic nanochannels. Anisotropic ion conductions of the layered and columnar ionic liquids were achieved for the macroscopically oriented samples. ${ }^{31-34}$ The intermolecular hydrogen bonds and ion-dipolar interactions play significant key roles in the formation of supramolecular structures and in the thermal stabilization of the liquid-crystalline phases. In the course of our studies, we envisaged that the protic salts composed of imidazole and organic acids could be organized into the hydrogen-bonded networks of mesomorphic diols owing to the presence of acidic exchangeable protons, leading to the production of a new family of proton-conductive supramolecular liquid crystals. Drummond and co-workers reported a fundamental study on the self-assembly of hexadecyltrimethylammonium bromide in protic ionic liquids as polar solvents. ${ }^{41}$ Hexagonal, cubic, and lamellar phases were observed in the protic ionic liquids obtained by the combination of primary amines and carboxylic acids. However, no proton conductivities of these liquid-crystalline assemblies have been reported so far.

Herein we report on the noncovalent supramolecular columnar and smectic liquid-crystalline assemblies composed
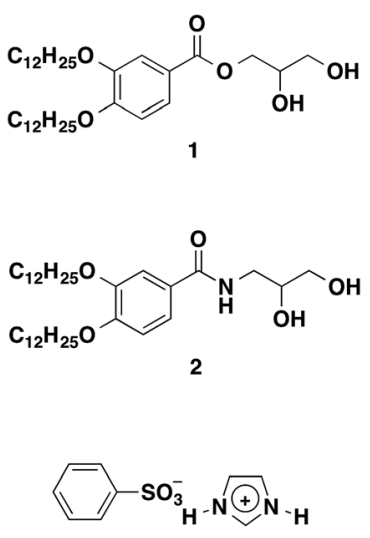

3

Fig. 2 Chemical structures of mesomorphic diols 1 and 2 and protic salt 3 . of wedge-shaped mesomorphic diols 1, 2 and protic salt 3 (Fig. 2). The confinement of $\mathbf{3}$ into the hydrogen-bonded networks of mesomorphic diols has led to a great enhancement of the ionic conductivity by about three orders of magnitude compared to that of protic salt $\mathbf{3}$ alone in the solid state.

\section{Results and discussion}

\section{Material design and synthesis}

Wedge-shaped glyceryl ester 1 and amide 2 (Fig. 2) were designed. We have expected the formation of various nanosegregated liquid-crystalline structures for the mixtures of the diols and protic salts. We previously found that imidazoliumbased ionic liquids were incorporated into the hydrogenbonded networks of amphiphilic diols in the liquid-crystalline phases. ${ }^{30-36}$ In the present work, we have employed noncovalent supramolecular approaches for the development of protonconducting materials based on a new protic salt. Compound 1 was synthesized by the condensation reaction of 3,4-bis(dodecyloxy)benzoic acid and 2,2-dimethyl-1,3-dioxolan-4-methanol in the presence of 1-ethyl-3-(3-dimethylaminopropyl)carbodiimide hydrochloride (EDC) and 4-dimethylaminopyridine (DMAP) as the condensation reagents and subsequent deprotection of the acetal. Compound 2 (ref. 42 and 43) was synthesized by a similar procedure using 3,4-bis(dodecyloxy)benzoic acid and 3-amino-1,2-propanediol. As a protic salt, imidazolium salt 3 (Fig. 2) was designed because of the expectation to provide an organic salt with a low melting point and high ionic conductivity due to a proton exchange between the imidazolium cations under anhydrous conditions as well as a strong delocalization of the anionic charge over the phenyl ring. Compound 3 was easily prepared by neutralization of imidazole with benzenesulfonic acid (ESI Fig. S1 and S2†).

\section{Liquid-crystalline properties}

The phase transition behaviour of compounds 1, 2 and twocomponent mixtures of the diols with protic salt $3[1 / 3(x)$ and $2 /$ $3(x), x$ denotes the mole $\%$ of $\mathbf{3}$ in the mixtures] was determined by polarized optical microscopic (POM) observation and differential scanning calorimetry (DSC) measurements together with X-ray diffraction (XRD) measurements. Compound 1 forms a columnar liquid-crystalline phase between 95 and $45{ }^{\circ} \mathrm{C}$ on cooling. A fan texture characteristic of the columnar phase is observed under POM observation. The wide-angle XRD pattern of 1 at $70{ }^{\circ} \mathrm{C}$ shows four peaks at 37.7, 24.9, 18.9, and $12.6 \AA$.

These peaks correspond to (100), (110), (200), and (300) diffractions, respectively.

The small-angle XRD pattern of 1 aligned homeotropically on a polyimide film at $70{ }^{\circ} \mathrm{C}$ shows diffraction spots with a six fold symmetry from the (100) plane (ESI Fig. S3†). These results indicate a two-dimensional hexagonal arrangement of columns. The intercolumnar distance $(a)$ of 1 is calculated to be $44 \AA$ by using the following equation: $a=2 \times d_{100} / \sqrt{ } 3$ (ESI Fig. S4 and $5 \dagger)$. Compound 2 also exhibits the hexagonal columnar $\left(\mathrm{Col}_{\mathrm{h}}\right)$ phase from 146 to $58{ }^{\circ} \mathrm{C}$ on cooling. The temperature range of the $\mathrm{Col}_{\mathrm{h}}$ phase of $\mathbf{2}$ is wider than that of $\mathbf{1}$, which is attributable 
to the amide hydrogen bonds. The intercolumnar distance of 2 is $46 \AA$ and is slightly larger than that of 1 (ESI Fig. S5 $\dagger$ ). Protic salt 3 shows the melting point at $105{ }^{\circ} \mathrm{C}$ and it crystallizes from the isotropic melt at $80{ }^{\circ} \mathrm{C}$ on cooling.

Compounds 1 and 2 are chemically stable in the presence of protic salt 3. No hydrolysis and ester exchange reactions for 1 and no cyclization of $\beta$-hydroxy amide to oxazoline for 2 were observed after heating the mixtures up to $150{ }^{\circ} \mathrm{C}$.

The phase transition behaviour of mixtures $1 / 3(x)$ and $2 / 3(x)$ up to $x=50$ during the cooling process is summarized in Fig. $3 \mathrm{a}$ and $\mathrm{b}$, respectively. The mixtures $\mathbf{1} / \mathbf{3}(x)$ containing less than or equal to $40 \mathrm{~mol} \%$ of 3 form the $\mathrm{Col}_{\mathrm{h}}$ phases, whereas the mixture $1 / 3(50)$ exhibits a smectic $A\left(S_{A}\right)$ phase from 98 to $40{ }^{\circ} \mathrm{C}$. The typical textures of the $\mathrm{Col}_{\mathrm{h}}$ and $\mathrm{S}_{\mathrm{A}}$ phases observed for $\mathbf{1} / \mathbf{3}(x)$ are shown in Fig. 4. A fan texture is seen for the mixture 1/3(30) in the $\mathrm{Col}_{\mathrm{h}}$ phase at $70{ }^{\circ} \mathrm{C}$ (Fig. 4a). The mixture $1 / 3(50)$ in the $\mathrm{S}_{\mathrm{A}}$ phase at $70{ }^{\circ} \mathrm{C}$ shows an oily streak texture (Fig. 4b), which is indicative of the defects of vertically oriented layered assemblies

(a)

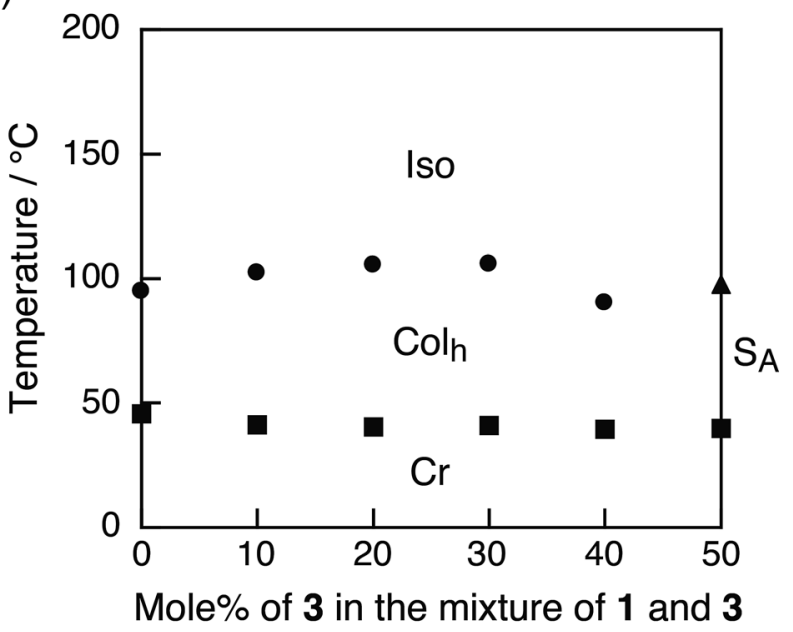

(b)

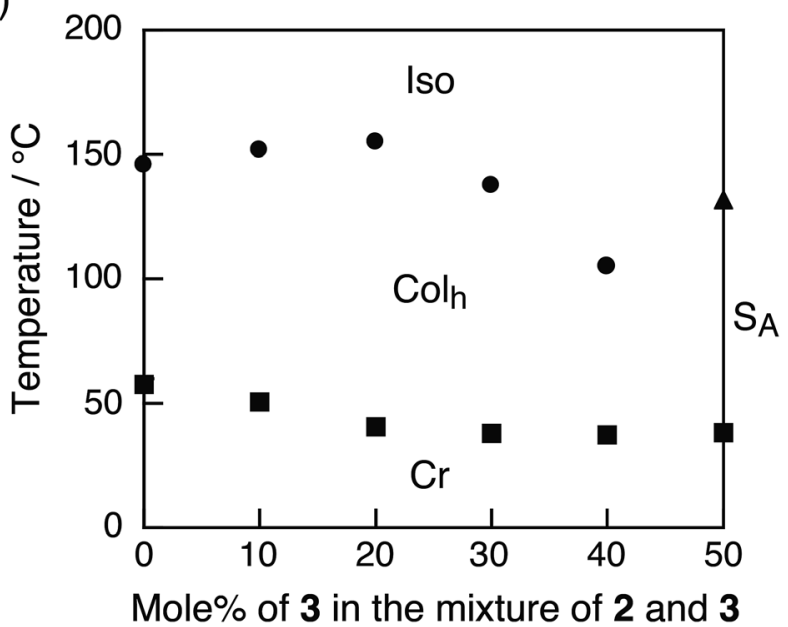

Fig. 3 Phase transition behaviour of (a) mixtures $1 / 3$ and (b) mixtures $2 / 3$ on cooling. The transition temperatures are taken at the onset points determined by DSC measurements on the cooling processes. $\mathrm{Cr}$ : crystalline; $\mathrm{Col}_{\mathrm{h}}$ : hexagonal columnar; Iso: isotropic liquid; $\mathrm{S}_{\mathrm{A}}$ : smectic A phase. (a)

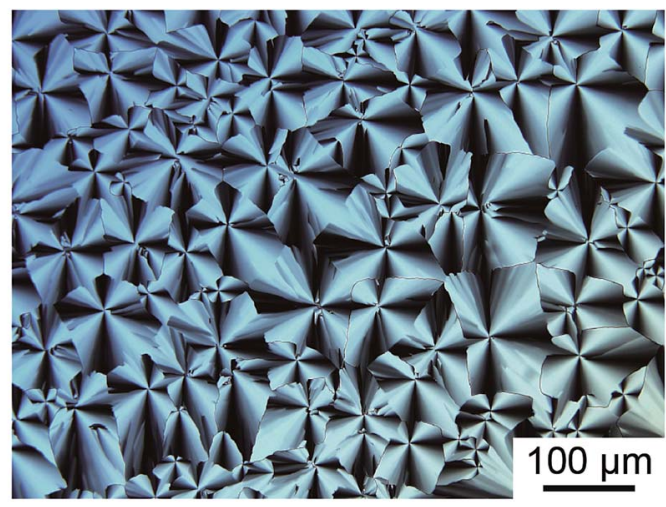

(b)

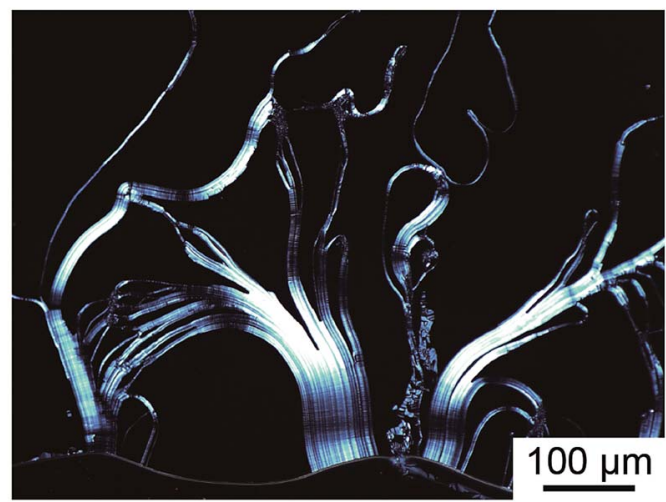

Fig. 4 POM images of (a) the mixture $1 / 3(30)$ in the Col $\mathrm{h}_{\mathrm{h}}$ phase at $70{ }^{\circ} \mathrm{C}$ and (b) the mixture $1 / 3(50)$ in the $S_{A}$ phase at $70{ }^{\circ} \mathrm{C}$.

on the glass substrate. The isotropization temperature of the $\mathrm{Col}_{\mathrm{h}}$ phases for the mixtures $\mathbf{1 / 3}(x)$ containing less than or equal to $30 \mathrm{~mol} \%$ of $\mathbf{3}$ becomes higher than that of $\mathbf{1}$ alone due to the formation of intermolecular hydrogen bonds. The intercolumnar distance and the average number of diol molecules 1 per cross-sectional slice of the columns $\left(n_{1}\right)$ increase with the increase of the concentration of 3 (ESI Fig. S5 and $6 \dagger$ ). For example, the value of $a$ for mixture 1/3(30) is $55 \AA$. The estimated values of $n_{1}$ for the mixture 1/3(30) and 1 alone are 13 and 8 , respectively. For the mixture $\mathbf{1} / \mathbf{3}(40)$, the isotropization temperature is lower than that of $\mathbf{1}$. This observation can be attributed to the less packing of 3 in the center of columns.

As for the mixtures $2 / 3(x)$ (Fig. 3b), the transition temperatures from the $\mathrm{Col}_{\mathrm{h}}$ to isotropic liquid (Iso) phase are higher than those of mixtures $\mathbf{1} / \mathbf{3}(x)$ owing to enhanced intermolecular interactions. Thermal stabilization of the $\mathrm{Col}_{\mathrm{h}}$ phases by mixing with 3 is also observed for $2 / 3(x)$ with $10-20 \mathrm{~mol} \%$ of 3 . Further increase of 3 in the mixture results in a remarkable decrease in the Iso- $^{-C_{h}}$ phase transition temperature. This result is presumably ascribed to the columnar distortion caused by steric hindrance due to the formation of hydrogen bonds between the amide group of 2 and the benzenesulfonate anion of 3. The intercolumnar distance of $2 / 3(x)$ and the average number of diols 2 per cross-sectional slice of the columns $\left(n_{2}\right)$ also show increasing trends with the increase of 3 , which are similar to that of $1 / 3(x)$ (ESI Fig. S5 and $7 \dagger$ ). On the other hand, the mixture $2 / 3(50)$ is thermally stabilized again by the formation of layered molecular assembly. 
The ${ }^{1} \mathrm{H}$ NMR spectrum of the equimolar mixture of diol 2 and protic salt 3 in $\mathrm{CDCl}_{3}$ is compared with those of single components 2 and 3 to examine the intermolecular interactions (Fig. 5). A downfield shift of the $\mathrm{C}(2)$ proton (H14) of the imidazolium cation of 3 from 8.82 to $8.89 \mathrm{ppm}$ is observed by the complexation of 2 and 3 . This result can be attributed to the formation of hydrogen bonds between the $\mathrm{C}(2)$ proton of the imidazolium cation and compound 2. As for the mixture $\mathbf{1}$ / $3(30)$, a similar downfield shift of the $\mathrm{C}(2)$ proton $(\mathrm{H} 14)$ of the imidazolium cation of 3 was seen (ESI Fig. S $8 \dagger$ ). In addition, the amide NH proton of 2 (H10) is also downfield shifted from 6.49 to $6.76 \mathrm{ppm}$ upon the complexation of 2 and 3, which is probably due to the hydrogen bonds between the amide $\mathrm{NH}$ proton and benzenesulfonate anion. A host-guest complexation of an aromatic oligoamide macrocycle and anhydrous $p$-toluenesulfonic acid was examined by ${ }^{1} \mathrm{H}$ NMR spectroscopy, ${ }^{44}$ which showed a downfield shift of the amide $\mathrm{NH}$ proton by the addition of sulfonic acid in $\mathrm{CDCl}_{3} / \mathrm{CD}_{3} \mathrm{OD}$. As for the carbonyl groups of mesomorphic compounds $\mathbf{1}$ and $\mathbf{2}$, no specific interactions with protic salt 3 in $\mathrm{CDCl}_{3}$ were detected by the ${ }^{13} \mathrm{C} \mathrm{NMR}$ spectroscopic measurements (ESI Fig. S9 and 10†).

FT-IR measurements at various temperatures were then conducted to examine the interactions between the mesomorphic diols and protic salt (ESI Fig. S11-18†). The $\mathrm{C}=\mathrm{O}$ stretching band of the amide group for 2 in the $\mathrm{Col}_{h}$ phase is observed at $1634 \mathrm{~cm}^{-1}$. This observation suggests that the amide carbonyl group involved in hydrogen bonding was not affected by the presence of protic salt 3 . In addition, for the ester compound 1 , no change in the $\mathrm{C}=\mathrm{O}$ stretching band of the ester group is seen for 1 and the mixtures $1 / 3(30)$ and 1/3(50). These results show the carbonyl groups in the amide or ester

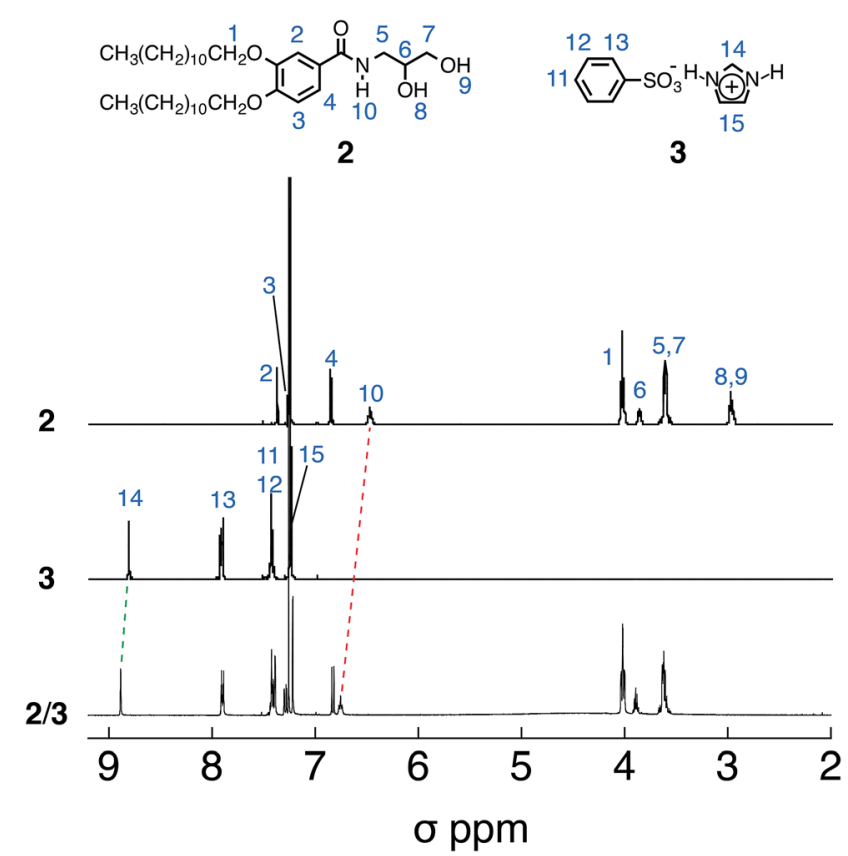

Fig. $5{ }^{1} \mathrm{H}$ NMR spectra of diol 2, protic salt 3, and the equimolar mixture of 2 and 3 . groups of $\mathbf{1}$ and $\mathbf{2}$ were not involved in the hydrogen bonding with protic salt 3 .

\section{Ion-conductive properties}

The ionic conductivities of liquid-crystalline assemblies containing protic salt 3 were measured as a function of temperature by an alternating current impedance method. The measurement cell is composed of a glass plate with comb-shaped gold electrodes and a cover glass. The sample in the isotropic liquid state was filled between the electrodes and cooled to the $\mathrm{Col}_{\mathrm{h}}$ phase. A random orientation of the columns was observed between the electrodes. Uniaxial orientation of the columnar assemblies was attainable after the polydomain columns were mechanically sheared within the cell (ESI Fig. S19†). The columns were aligned parallel to the direction of shearing force. We succeeded in measuring the anisotropic conductivities along the direction parallel $\left(\sigma_{\|}\right)$and perpendicular $\left(\sigma_{\perp}\right)$ to the columnar axis for the columnar assemblies. On the other hand, a vertical alignment of the $S_{A}$ assemblies between the electrodes was spontaneously formed for the mixtures $1 / 3(50)$ and $2 / 3(50)$, which allowed for the measurement of the ionic conductivities along the direction parallel to the layers $\left(\sigma_{\|}\right)$. The anisotropy of the $S_{A}$ phases cannot be measured because of the polydomain formation in indium tin oxide (ITO)-based sandwiched cells. ${ }^{30}$

Fig. 6 shows the ionic conductivities of the mixtures $1 / 3(30)$ and $2 / 3(30)$ with the columnar structures aligned parallel to the direction of the applied electric field, together with those of protic salt 3 showing the melting point at $105{ }^{\circ} \mathrm{C}$. The selfassembly of $\mathbf{3}$ and diols $\mathbf{1}$ and $\mathbf{2}$ leads to a drastic increase in ionic conductivity, whereas 3 alone shows low conductivities on the order of $10^{-7}-10^{-8} \mathrm{~S} \mathrm{~cm}^{-1}$ in the crystalline phase. The values of ionic conductivities for the mixtures $1 / 3(30)$ and $2 /$

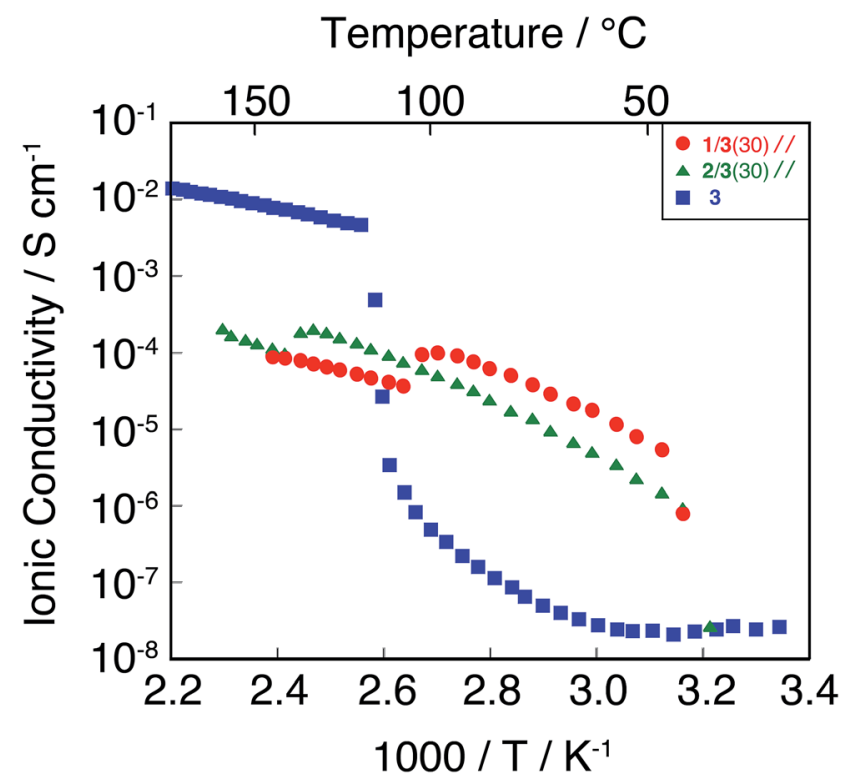

Fig. 6 Ionic conductivities of protic salt $3(\boldsymbol{\square})$ and the mixtures 1/3(30) $(\mathbf{O})$ and $2 / 3(30)(\mathbf{\Delta})$ as a function of temperature. For the mixtures, the conductivities along the direction parallel to the columnar axis $\left(\sigma_{\|}\right)$are plotted. 
3(30) at $70{ }^{\circ} \mathrm{C}$ are $2.9 \times 10^{-5} \mathrm{~S} \mathrm{~cm}^{-1}\left(\sigma_{\|}\right)$and $9.6 \times 10^{-6} \mathrm{~S} \mathrm{~cm}^{-1}$ $\left(\sigma_{\|}\right)$, respectively, which are 740 times and 250 times higher than those of protic salt $3\left(3.9 \times 10^{-8} \mathrm{~S} \mathrm{~cm}^{-1}\right.$ at $\left.70{ }^{\circ} \mathrm{C}\right)$. These results suggest that the protic salt has more mobile states in the columnar assemblies. A drop in the conductivity during the $\mathrm{Col}_{\mathrm{h}}$-to-Iso phase transitions is observed for the mixtures, which is attributed to the collapse of one-dimensional ion-transport pathways. The mixture $2 / 3(30)$ in the $\mathrm{Col}_{\mathrm{h}}$ phase exhibits slightly lower ionic conductivities compared to the mixture $1 / 3(30)$ in the $\mathrm{Col}_{\mathrm{h}}$ phase.

We also examined the anisotropic ionic conductivities of the $\mathrm{Col}_{\mathrm{h}}$ assemblies forming monodomains for the mixtures 1/3(20) and $\mathbf{1} / \mathbf{3}(30)$ and the conductivities parallel to the layers for $\mathbf{1} /$ 3(50) exhibiting the $S_{A}$ phase (Fig. 7). The increase in the concentration of 3 in the mixtures leads to the increase of conductivities. The $S_{A}$ phase shows higher conductivities than those of the $\mathrm{Col}_{\mathrm{h}}$ phases. The conductivities parallel to the columnar axis $\left(\sigma_{\|}\right)$for $\mathbf{1 / 3}(20)$ and $\mathbf{1} / 3(30)$ are higher than those perpendicular to the columnar axis $\left(\sigma_{\perp}\right)$ for $\mathbf{1} / \mathbf{3}(20)$ and $\mathbf{1} / \mathbf{3}(30)$, because the alkyloxyphenyl parts function as insulating parts. For example, the value of $\sigma_{\|}$for the mixture $1 / 3(20)$ is $1.5 \times 10^{-5}$ $\mathrm{S} \mathrm{cm}^{-1}$ at $70{ }^{\circ} \mathrm{C}$, which is 60 times higher than that of $\sigma_{\perp}$. As for the mixture $1 / 3(30)$, the values of $\sigma_{\|}$and $\sigma_{\perp}$ at $70{ }^{\circ} \mathrm{C}$ are $2.9 \times$ $10^{-5}$ and $7.9 \times 10^{-7} \mathrm{~S} \mathrm{~cm}^{-1}$, respectively. The value of anisotropy $\left(\sigma_{\|} / \sigma_{\perp}\right)$ for $\mathbf{1} / \mathbf{3}(30)$ is 37 . The anisotropy shows a decreasing trend with the increase in the concentration of protic salt $\mathbf{3}$, which is probably due to the leak of ions from the center of columns upon the formation of more fluid columns. The anisotropy of conductivity disappears when the samples become isotropic liquids.

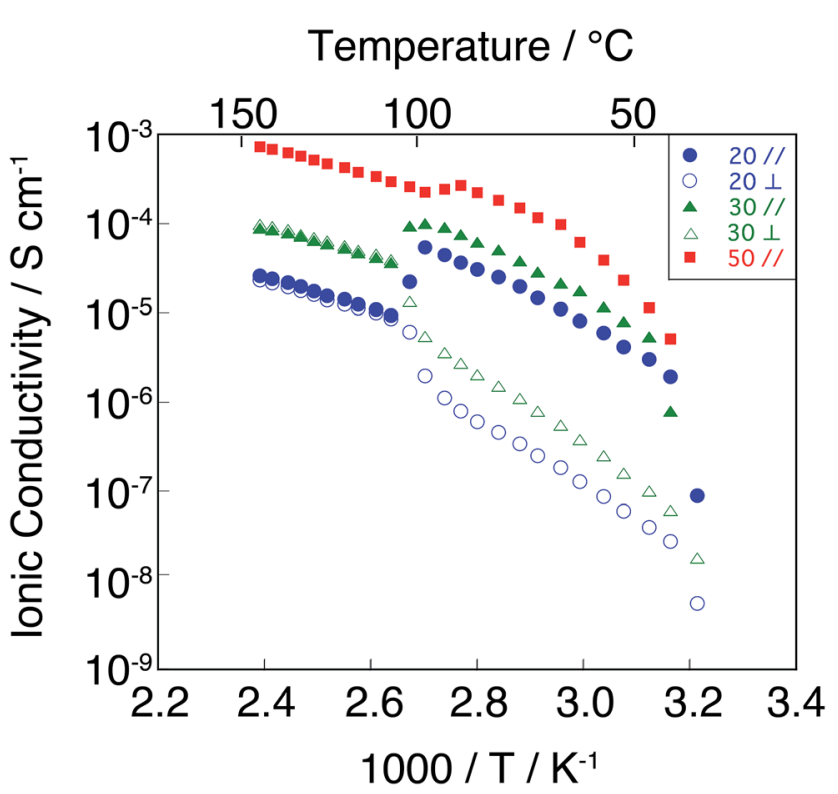

Fig. 7 Ionic conductivities of mixtures $1 / 3(20)$ and $1 / 3(30)$ forming the Coln phases with uniaxial planar orientations and mixture $1 / 3(50)$ exhibiting the $S_{A}$ phase with a vertical orientation. Parallel direction of the columnar axis $(\|)$ : $(\mathbf{O})$ for $1 / 3(20)$ and $(\Delta)$ for $1 / 3(30)$; perpendicular direction of the columnar axis $(\perp)$ : $(O)$ for $1 / 3(20)$ and $(\triangle)$ for $1 / 3(30)$; parallel direction of the layer ( $\mathbf{\square})$ for $1 / 3(50)$.

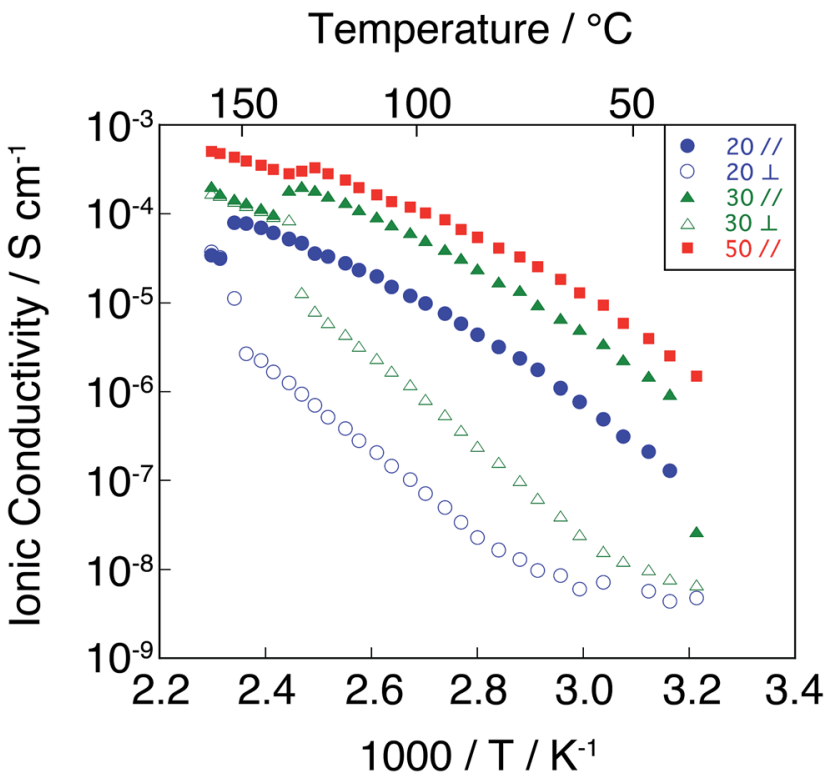

Fig. 8 Ionic conductivities of mixtures $2 / 3(20)$ and $2 / 3(30)$ forming the $\mathrm{Col}_{h}$ phases with uniaxial planar orientations and mixture 2/3(50) exhibiting the $S_{A}$ phase with a vertical orientation. Parallel direction of the columnar axis $(\|)$ : $(\mathbf{O})$ for $2 / 3(20)$ and $(\mathbf{\Delta})$ for $2 / 3(30)$; perpendicular direction of the columnar axis $(\perp)$ : $(\bigcirc)$ for $2 / 3(20)$ and $(\triangle)$ for 2/3(30); parallel direction of the layer $(\boldsymbol{\square})$ for $2 / 3(50)$.

Fig. 8 shows the effects of the ratio of 3 on anisotropic ionic conductivities for the mixtures $2 / 3(20)$ and $2 / 3(30)$ forming the $\mathrm{Col}_{\mathrm{h}}$ phases and the conductivities of $2 / 3(50)$ showing the $\mathrm{S}_{\mathrm{A}}$ phase as a function of temperature. The conductivities also increase with the increase of 3 in the mixtures. As with the $\mathrm{Col}_{h}$ phases of $1 / 3(x)$, the value of anisotropy $\left(\sigma_{\|} / \sigma_{\perp}\right)$ in the $\mathrm{Col}_{\mathrm{h}}$ phases of $2 / 3(x)$ decreases with the increase of 3 . The ionic conductivities of all the mixtures $2 / 3(x)$ are lower than those of $1 / 3(x)$. However, the anisotropy $\left(\sigma_{\|} / \sigma_{\perp}\right)$ of the $2 / 3(x)$ in the $\mathrm{Col}_{\mathrm{h}}$ phases shows the increasing trend compared to those of $1 / 3(x)$. For example, the values of anisotropy $\left(\sigma_{\|} / \sigma_{\perp}\right)$ of $1 / 3(10)$ and $2 /$ $3(10)$ are 110 and 310 at $80{ }^{\circ} \mathrm{C}$, respectively. The higher anisotropy for $2 / 3(10)$ may be attributed to the inhibition of the leakage of ions across the columns stabilized by the amide hydrogen bonds.

\section{Conclusion}

We have demonstrated that an imidazolium-based protic salt is self-organized into the hydrogen bonded networks of mesomorphic 1,2-diols. Noncovalent supramolecular columnar and smectic liquid-crystalline structures forming $1 \mathrm{D}$ and $2 \mathrm{D}$ protic channels are induced depending on the mixing ratio of the protic salt and diols. The induction of these liquid-crystalline structures is ascribed to the formation of intermolecular hydrogen bonds and nanosegregation. The confined protic salt in liquid-crystalline phases has been found to exhibit enhanced conductivities by three orders of magnitude compared to the protic salt alone in the crystalline state. The use of intermolecular interactions is a significant way to improve the ion- 
conducting properties. We have also achieved 1D anisotropic proton conduction for the macroscopically aligned columnar assemblies, which is simply obtained by the application of mechanical shear force.

Protic ionic liquids and protic salts are attractive anhydrous proton conductors for fuel cells. The confinement of these protic materials into ordered liquid-crystalline nanostructures would be a promising approach to the development of efficient anhydrous proton conductors. The use of ionic intermolecular interactions for the construction of functional materials may be one of the promising ways for these approaches. ${ }^{7,8,45-49}$

\section{Experimental}

\section{General}

${ }^{1} \mathrm{H}$ NMR spectra were obtained using a JEOL-ECX 400 at 400 $\mathrm{MHz}$ in $\mathrm{CDCl}_{3}$ and DMSO- $\mathrm{d}_{6}$, and ${ }^{13} \mathrm{C}$ NMR spectra were obtained using a JEOL-ECX 400 at $100 \mathrm{MHz}$ in $\mathrm{CDCl}_{3}$. Chemical shifts of ${ }^{1} \mathrm{H}$ and ${ }^{13} \mathrm{C}$ NMR signals were referenced to $\mathrm{Me}_{4} \mathrm{Si}(\delta=$ $0.00 \mathrm{ppm})$ and $\mathrm{CDCl}_{3}(\delta=7.26 \mathrm{ppm})$ as internal standards in $\mathrm{CDCl}_{3}$ and DMSO $(\delta=2.50 \mathrm{ppm})$ as internal standards in DMSO. IR spectra were obtained using a JASCO FT/IR 6100 spectrometer. Temperature variable IR spectra were obtained using a JASCO FT/IR 6100 and a JASCO IRT-5000 equipped with a METTLER TOLEDO FP90 Central Processor and a FP82HT Hotstage. Matrix-assisted laser desorption ionization-time-offlight mass spectra (MALDI-TOF-MS) were taken on a BRUKER autoflex ${ }^{\mathrm{TM}}$ speed spectrometer using dithranol as the matrix. Elemental analyses were carried out with a Perkin-Elmer CHNS/ O 2400 apparatus and a Yanaco MT-6 CHN autocorder. An Olympus BX-51 polarizing optical microscope equipped with a Mettler FP82 HT hot-stage was used for visual observation. The phase transition behaviour of the materials was examined by differential scanning calorimetry (DSC) using a Netzsch DSC204 Phoenix (scanning rate of $10 \mathrm{~K} \mathrm{~min}^{-1}$ ). X-ray diffraction (XRD) patterns were obtained by using a Rigaku RINT-2500 diffractometer with a heating stage using Ni-filtered $\mathrm{CuK} \alpha$ radiation.

\section{Materials}

All starting materials were obtained commercially and used as received.

\section{Synthesis of 2,3-dihydroxypropyl-3,4-bis(dodecyloxy)benzoate} (1)

A mixture of 3,4-bis(dodecyloxy)benzoic acid ( $2.00 \mathrm{~g}, 4.08 \mathrm{mmol}$ ), 2,2-dimethyl-1,3-dioxolan-4-methanol (0.64 g, $4.89 \mathrm{mmol})$, EDC (0.94 g, $4.89 \mathrm{mmol}$ ), and DMAP (99.58 mg, $0.82 \mathrm{mmol}$ ) in $\mathrm{CH}_{2} \mathrm{Cl}_{2}$ $(100 \mathrm{~mL})$ was stirred overnight at ambient temperature. The reaction mixture was added to brine and extracted with ethyl acetate. The organic phase was then dried over anhydrous magnesium sulfate, filtered, and evaporated in vacuo. The residue was purified by flash column chromatography (silica gel, eluent: hexane : ethyl acetate $=9: 1)$ to give (2,2-dimethyl-1,3dioxolan-4-yl)methyl 3,4-bis(dodecyloxy)benzoate (1.8 g, 72.1\%) as a liquid.
The obtained acetal (1.8 g, $2.53 \mathrm{mmol})$ was cleaved by $p$-toluenesulfonic acid $(2.26 \mathrm{~g}, 11.90 \mathrm{mmol})$ in ethanol/water $(19: 1$ $\mathrm{v} / \mathrm{v}, 40 \mathrm{~mL}$ ) by stirring at $60^{\circ} \mathrm{C}$ for $3 \mathrm{~h}$. The reaction mixture was added to a saturated $\mathrm{NH}_{4} \mathrm{Cl}$ aq. solution and extracted with ethyl acetate. Then the organic phase was dried over anhydrous magnesium sulfate, filtered, and evaporated in vacuo. The residue was purified by flash column chromatography (silica gel, eluent: ethyl acetate : methanol $=9: 1$ ) and recrystallized from methanol/ethyl acetate to give 2,3-dihydroxypropyl 3,4bis(dodecyloxy)benzoate $1(1.4 \mathrm{~g}, 86 \%)$ as a white solid. ${ }^{1} \mathrm{H}$ NMR $\left(400 \mathrm{MHz} \mathrm{CDCl}_{3}\right): \delta=7.67(\mathrm{~d}, J=8.8 \mathrm{~Hz}, 2 \mathrm{H}), 7.54(\mathrm{~s}, 1 \mathrm{H}), 6.89$ (d, 7H), $4.43(\mathrm{~m}, 2 \mathrm{H}), 4.10-4.05(\mathrm{~m}, 5 \mathrm{H}), 3.81-3.65(\mathrm{~m}, 2 \mathrm{H}), 2.71$ $(\mathrm{d}, J=5.2, \mathrm{~Hz} 1 \mathrm{H}), 2.24(\mathrm{t}, J=6.0 \mathrm{~Hz}, 1 \mathrm{H}), 1.85(\mathrm{~m}, 4 \mathrm{H}), 1.49(\mathrm{~m}$, $4 \mathrm{H}), 1.42-1.21(\mathrm{~m}, 32 \mathrm{H}) 0.90(\mathrm{t}, J=6.4 \mathrm{~Hz}, 6 \mathrm{H}) .{ }^{13} \mathrm{C}$ NMR $(100$ $\left.\mathrm{MHz}, \mathrm{CDCl}_{3}\right): \delta=167.25,153.76,148.69,123.96,121.64,114.39$, $111.93,70.60,69.44,69.13,65.71,63.46,32.05,29.82,29.79$, $29.76,29.54,29.50,29.29,29.14,26.13,26.08,22.82,14.26$. IR (KBr): 3469, 3366, 3082, 2954, 2922, 2872, 2850, 2748, 2683, 2619, 1714, 1600, 1588, 1519, 1468, 1432, 1389, 1348, 1300, 1275, 1226, 1146, 1134, 1110, 1090, 1067, 1049, 1022, 992, 950, 930, 882, 829, $813 \mathrm{~cm}^{-1}$. MS (MALDI-TOF): calcd for $[\mathrm{M}+\mathrm{Na}]^{+}$, 587.43; found, 587.45. Elemental analysis: calcd (\%) for $\mathrm{C}_{34} \mathrm{H}_{60} \mathrm{O}_{6}$ : C 72.30, $\mathrm{H}$ 10.71. Found C 72.52, H 10.44.

\section{Synthesis of $N$-(2,3-dihydroxypropyl)-3,4-bis(dodecyloxy) benzamide (2)}

A mixture of 3,4-bis(dodecyloxy)benzoic acid $(0.50 \mathrm{~g}, 1.02$ $\mathrm{mmol})$, 3-amino-1,2-propanediol (0.11 g, $1.22 \mathrm{mmol})$, EDC (0.23 $\mathrm{g}, 1.22 \mathrm{mmol}$ ), and DMAP (24.89 $\mathrm{mg}, 0.20 \mathrm{mmol})$ in $\mathrm{CH}_{2} \mathrm{Cl}_{2}(100$ $\mathrm{mL}$ ) was stirred overnight at ambient temperature. The reaction mixture was added to brine and extracted with ethyl acetate. The organic phase was then dried over anhydrous magnesium sulfate, filtered, and evaporated in vacuo. The residue was purified by flash column chromatography (silica gel, eluent: ethyl acetate : methanol $=9: 1)$ and recrystallized from methanol/ethyl acetate to give $N$-(2,3-dihydroxypropyl)-3,4-bis(dodecyloxy)benzamide $2(0.43 \mathrm{~g}, 75 \%)$ as a white solid.

\section{Synthesis of imidazolium benzenesulfonate (3)}

A solution of imidazole $(0.24 \mathrm{mg}, 3.59 \mathrm{mmol})$ in $\mathrm{CHCl}_{3}(20 \mathrm{~mL})$ was added to a solution of benzenesulfonic acid $(0.67 \mathrm{~g}, 3.59$ $\mathrm{mmol})$ in $\mathrm{CHCl}_{3}(20 \mathrm{~mL})$. The resulting precipitate was collected by filtration, washed with $\mathrm{CHCl}_{3}$, and dried in a vacuum oven at $70{ }^{\circ} \mathrm{C}$ for $8 \mathrm{~h}$ to give $3(0.66 \mathrm{~g}, 73 \%)$ as a white solid. ${ }^{1} \mathrm{H}$ NMR (400 $\left.\mathrm{MHz} \mathrm{CDCl}_{3}\right): \delta=8.83(\mathrm{~s}, 1 \mathrm{H}), 7.90(\mathrm{dd}, J=8.0 \mathrm{~Hz}, 2 \mathrm{H}), 7.41(\mathrm{~s}$, $2 \mathrm{H}), 7.40(\mathrm{~s}, 1 \mathrm{H}), 7.22$ (s, 2H). ${ }^{13} \mathrm{C} \mathrm{NMR}\left(100 \mathrm{MHz}, \mathrm{CDCl}_{3}\right): \delta=$ 144.02, 134.60, 130.76, 128.62, 125.86, 118.93. IR (KBr): 3438, 3155, 2993, 2863, 2659, 1647, 1636, 1592, 1446, 1215, 1189, 1128, 1099, 1071, 1053, 1037, 1018, 998, 972, 904, 849, 828. Elemental analysis: calcd (\%) for $\mathrm{C}_{9} \mathrm{H}_{10} \mathrm{~N}_{2} \mathrm{O}_{3} \mathrm{~S}$ : C 47.78, $\mathrm{H} 4.46$, $\mathrm{N} 12.38$ found $\mathrm{C} 47.60, \mathrm{H} 4.38, \mathrm{~N} 12.18$.

\section{Preparation of the mixtures}

A $\mathrm{CHCl}_{3}$ solution of diol compound $\mathbf{1}$ or $\mathbf{2}$ was added to a requisite amount of a $\mathrm{CHCl}_{3}$ solution of protic salt 3 . After all compounds were dissolved in $\mathrm{CHCl}_{3}$ by heating, the solvent was 
removed by evaporation. The resulting mixture was dried in a vacuum oven at $70{ }^{\circ} \mathrm{C}$ for $4 \mathrm{~h}$.

\section{Acknowledgements}

This study was partially supported by the Grant-in-Aid for Scientific Research (No. 22107003) in the Innovative Area of "Fusion Materials" (Area No. 2206) from The Ministry of Education, Culture, Sports, Science and Technology (MEXT). M. Y. is grateful for financial support from the Grant-in-Aid for Young Scientists (A) (No. 25708013) from the Japan Society for the Promotion of Science (JSPS) and The Noguchi Institute.

\section{Notes and references}

1 M. F. H. Schuster and W. H. Meyer, Annu. Rev. Mater. Res., 2003, 33, 233-261.

2 K. Miyatake, B. Bae and M. Watanabe, Polym. Chem., 2011, 2, 1919-1929.

3 M. Rikukawa and K. Sanui, Prog. Polym. Sci., 2000, 25, 14631502.

4 T. Yasuda and M. Watanabe, MRS Bull., 2013, 38, 560-566.

5 J. Miyake, M. Watanabe and K. Miyatake, Polym. J., 2014, 46, 656-663.

6 K. A. Mauritz and R. B. Moore, Chem. Rev., 2004, 104, 45354585.

7 Handbook of Liquid Crystals, ed. J. W. Goodby, P. J. Collings, T. Kato, C. Tschierske, H. Gleeson and P. Raynes, Wiley-VCH, Weinheim, Germany, 2nd edn, 2014.

8 T. Kato, N. Mizoshita and K. Kishimoto, Angew. Chem., Int. Ed., 2006, 45, 38-68.

9 B.-K. Cho, RSC Adv., 2014, 4, 395.

10 V. Percec, G. Johansson, J. Heck, G. Ungar and S. V Batty, J. Chem. Soc., Perkin Trans. 1, 1993, 13, 1411-1420.

11 O. Ikkala and G. ten Brinke, Chem. Commun., 2004, 21312137.

12 R. Mäki-Ontto, K. de Moel, E. Polushkin, G. A. van Ekenstein, G. ten Brinke and O. Ikkala, Adv. Mater., 2002, 14, 357-361.

13 K. D. Kreuer, A. Fuchs, M. Ise, M. Spaeth and J. Maier, Electrochim. Acta, 1998, 43, 1281-1288.

14 M. F. H. Schuster, W. H. Meyer, M. Schuster and K. D. Kreuer, Chem. Mater., 2004, 16, 329-337.

15 R. Subbaraman, H. Ghassemi and T. A. Zawodzinski Jr., J. Am. Chem. Soc., 2007, 129, 2238-2239.

16 M. Armand, F. Endres, D. R. MacFarlane, H. Ohno and B. Scrosati, Nat. Mater., 2009, 8, 621-629.

17 T. L. Greaves and C. J. Drummond, Chem. Rev., 2008, 108, 206-237.

18 W. Xu and C. A. Angell, Science, 2003, 302, 422-425.

19 J.-P. Belieres and C. A. Angell, J. Phys. Chem. B, 2007, 111, 4926-4937.

20 M. A. B. H. Suasan, A. Noda, S. Mitsushima and M. Watanabe, Chem. Commun., 2003, 938-939.

21 A. Noda, M. A. Bin Hasan Susan, K. Kudo, S. Mitsushima, K. Hayamizu and M. Watanabe, J. Phys. Chem. B, 2003, 107, 4024-4033.
22 S.-Y. Lee, A. Ogawa, M. Kanno, H. Nakamoto, T. Yasuda and M. Watanabe, J. Am. Chem. Soc., 2010, 132, 9764-9773.

23 C.-F. Chow, V. A. L. Roy, Z. Ye, M. H. W. Lam, C. S. Lee and K. C. Lau, J. Mater. Chem., 2010, 20, 6245-6249.

24 S. Tan, C. Wang, T. Liang, W. Huang and Y. Wu, J. Mol. Struct., 2013, 1045, 15-19.

25 S. Tan, C. Wang and Y. Wu, J. Mater. Chem. A, 2013, 1, 10221025.

26 D. Basak, S. Christensen, S. K. Surampudi, C. Versek, D. T. Toscano, M. T. Tuominen, R. C. Hayward and D. Venkataraman, Chem. Commun., 2011, 47, 5566-5568.

27 D. Basak, C. Versek, J. A. Harvey, S. Christensen, J. Hillen, S. M. Auerbach, M. T. Tuominen and D. Venkataraman, $J$. Mater. Chem., 2012, 22, 20410-20417.

28 Y. Chen, M. Thorn, S. Christensen, C. Versek, A. Poe, R. C. Hayward, M. T. Tuominen and S. Thayumanavan, Nat. Chem., 2010, 2, 503-508.

29 S. Ueda, J. Kagimoto, T. Ichikawa, T. Kato and H. Ohno, Adv. Mater., 2011, 23, 3071-3074.

30 B. Soberats, M. Yoshio, T. Ichikawa, S. Taguchi, H. Ohno and T. Kato, J. Am. Chem. Soc., 2013, 135, 15286-15289.

31 M. Yoshio, T. Mukai, K. Kanie, M. Yoshizawa, H. Ohno and T. Kato, Adv. Mater., 2002, 14, 351-354.

32 M. Yoshio, T. Mukai, M. Yoshizawa, H. Ohno and T. Kato, Mol. Cryst. Liq. Cryst., 2004, 413, 99-108.

33 H. Shimura, M. Yoshio, K. Hoshino, T. Mukai, H. Ohno and T. Kato, J. Am. Chem. Soc., 2008, 130, 1759-1765.

34 A. Yamashita, M. Yoshio, S. Shimizu, T. Ichikawa, H. Ohno and T. Kato, J. Polym. Sci., Part A: Polym. Chem., 2015, 53, 366-371.

35 T. Ichikawa, M. Yoshio, S. Taguchi, J. Kagimoto, H. Ohno and T. Kato, Chem. Sci., 2012, 3, 2001-2008.

36 T. Ichikawa, K. Fujimura, M. Yoshio, T. Kato and H. Ohno, Chem. Commun., 2013, 49, 11746-11748.

37 M. Yoshio, T. Mukai, K. Kanie, M. Yoshizawa, H. Ohno and T. Kato, Chem. Lett., 2002, 320-321.

38 J. Sakuda, M. Yoshio, T. Ichikawa, H. Ohno and T. Kato, New J. Chem., 2015, 39, 4471-4477.

39 B. Soberats, M. Yoshio, T. Ichikawa, H. Ohno and T. Kato, J. Mater. Chem. A, 2015, 3, 11232-11238.

40 D. Högberg, B. Soberats, S. Uchida, M. Yoshio, L. Kloo, H. Segawa and T. Kato, Chem. Mater., 2014, 26, 6496-6502.

41 T. L. Greaves, A. Weerawardena, C. Fong and C. J. Drummond, Langmuir, 2007, 23, 402-404.

42 K. Borisch, S. Diele, P. Göring, H. Kresse and C. Tschierske, J. Mater. Chem., 1998, 8, 529-543.

43 C. Tschierske, Angew. Chem., Int. Ed., 2013, 52, 8828-8878.

44 H. Jiang, J.-M. Léger, P. Guionneau and I. Huc, Org. Lett., 2004, 6, 2985-2988.

45 C. F. J. Faul and M. Antonietti, Adv. Mater., 2003, 15, 673683.

46 Z. Wei, T. Laitinen, B. Smarsly, O. Ikkala and C. F. J. Faul, Angew. Chem., Int. Ed., 2005, 44, 751-756.

47 T. Kato, Angew. Chem., Int. Ed., 2010, 49, 7847-7848.

48 S. Chen and S. H. Eichhorn, Isr. J. Chem., 2012, 52, 830-843.

49 Y. Uchida, T. Matsumoto, T. Akita and N. Nishiyama, J. Mater. Chem. C, 2015, 3, 6144-6147. 